\title{
Maren Waike-Koormann, Elfriede Lohse-Wächtler und Grethe Jürgens. Ich-Bildungen und Rezeptionsverläufe zweier Künstlerinnen des 20.Jahrhunderts.
}

Héloïse Elisabeth Ducatteau

\section{OpenEdition}

Édition électronique

URL : https://journals.openedition.org/ifha/11504

DOI : 10.4000/ifha. 11504

ISSN : 2198-8943

Éditeur

IFRA - Institut franco-allemand (sciences historiques et sociales)

\section{Référence électronique}

Héloïse Elisabeth Ducatteau, « Maren Waike-Koormann, Elfriede Lohse-Wächtler und Grethe Jürgens. IchBildungen und Rezeptionsverläufe zweier Künstlerinnen des 20. Jahrhunderts. », Revue de l'IFHA [En ligne], Date de recension, mis en ligne le 25 octobre 2021, consulté le 13 décembre 2021. URL : http:// journals.openedition.org/ifha/11504; DOI : https://doi.org/10.4000/ifha.11504

Ce document a été généré automatiquement le 13 décembre 2021.

(CIFHA 
Maren Waike-Koormann, Elfriede Lohse-Wächtler und Grethe Jürgens. Ich-Bildungen und Rezeptionsverläufe zweier Künstlerinnen des 20.Jahrhunderts.

Héloïse Elisabeth Ducatteau

\section{RÉFÉRENCE}

Maren Waike-Koormann, Elfriede Lohse-Wächtler und Grethe Jürgens. Ich-Bildungen und Rezeptionsverläufe zweier Künstlerinnen des 20. Jahrhunderts, Baden-Baden: Tectum, 2019, 490 p, 66,99€. 


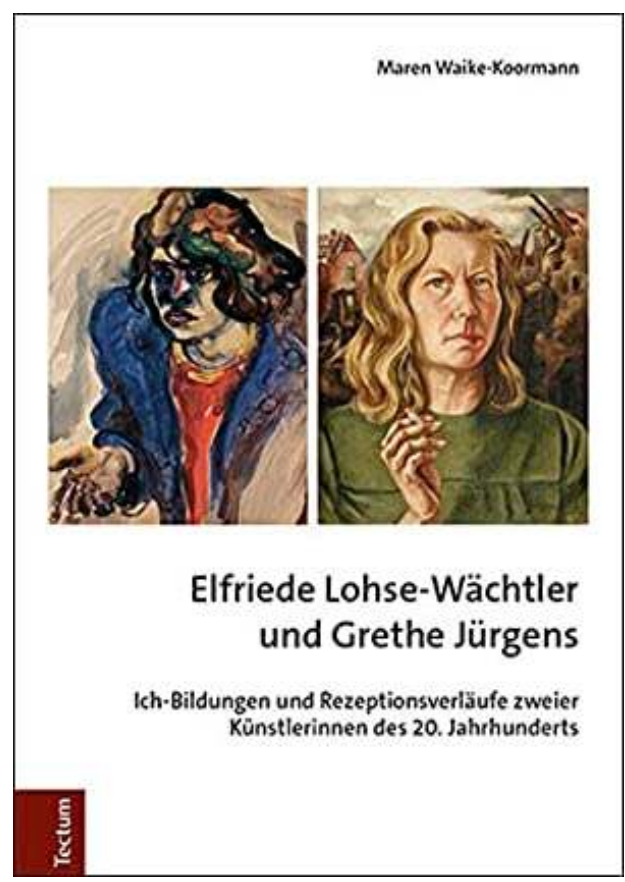

L'ouvrage recensé est le fruit d'une thèse de doctorat soutenue en 2017 à l'Université de Brême sous la direction de Rainer Stamm et de Christiane Keim. Comme les remerciements le signalent, le financement a été assuré par la FAZIT-Stiftung et par l'activité professionnelle de l'autrice dans le secteur muséal. C'est d'ailleurs par ce biais qu'elle est entrée en contact avec l'œuvre d'Elfriede Lohse-Wächtler, à l'occasion d'une exposition au musée Zeppelin de Friedrichshafen en 2008 sous l'égide d'Ursula Zeller et de Dirk Blübaum. Cette préface, au-delà des conventions, nous éclaire sur la localisation des archives et des spécialistes de la peintresse encore largement ignorée dans l'Hexagone et même plus largement dans l'aire panromane. Aucune publication n'a en effet été décelée en langue française sur l'artiste hormis un article issu de la presse généraliste (Jean-Jacques Régibier, « La République de Weimar révélée par ses peintres ", L'Humanité, 2018, URL : https://humanite.fr/la-republique-de-weimar-revelee-parses-peintres-649006). Cet article relate l'exposition qui s'est tenue à la Schirn Kunst Halle de Francfort-sur-le-Main où Elfriede Lohse-Wächtler a figuré aux côtés de d'autres peintresses : Anna Nagel, Jeanne Mammen, Hilde Rakebrand. Pour la partie italophone, l'on se contentera de Francesca Santucci ( L'inferno di Elfriede LohseWächtler ", Il male al cinema, edizioni Lulu, Mostra d'Arte Cinematografica di Venezia, 2015) dont on regrettera le manque de rigueur scientifique mais dont on appréciera la pédagogie. Si l'artiste, dont le prénom nous rappelle presque inévitablement l'écrivaine des Exclus et d'Au pays des nuées, a déjà fait l'objet d'un certain nombre de publications outre-Rhin que ce soit sous forme de catalogues d'exposition, de compterendus, d'articles isolés et même d'une monographie en 1996 (Georg Reinhardt, Im Malstrom des Lebens versunken: Elfriede Lohse-Wächtler 1899-1940, Leben und Werk, Köln: Wiener Verlag, 1996, l'ouvrage a fait l'objet d'une recension : Christiane Hertel, Woman's Art Journal, $\mathrm{n}^{\circ}$ 21, 2000, p. 50-53. https://doi.org/10.2307/1358753), l'analyse semble embourbée dans l'étiquetage fatal-tragique attribué à Lohse-Wächtler. Une autre thèse de doctorat postérieure à la monographie présente (Daniela Weinstock, Elfriede Lohse-Wächtler (1899-1940). Geschätzt - geächtet - verfolgt : mit einem Katalog ihrer Werke, Johannes Gutenberg-Universität Mainz, 2020. http://doi.org/10.25358/ 
openscience-5194) se concentre quant à elle sur son enfermement psychiatrique dans ses huit dernières années. Le fait que Grethe Jürgens, plasticienne de la même période et objet d'une thèse doctorale en 2014 (Heike Scholz, Am Rande des Blickfeldes. Grethe Jürgens - eine Künstlerin der zwanziger Jahre in Hannover, Philipps-Universität Marburg, 2000. https://doi.org/10.17192/z2001.0394), soit aussi réduite à des interprétations ensablées, que les autoportraits et les portraits de couples soient récurrents dans sa peinture entre 1920 et 1940 justifie la mise en parallèle des deux.

Un article paru à l'orée de notre siècle (Carole Muysers \& Ada Raev \& Ulrike WolfThomsen, "Die Biographie ist tot - es lebe die Biographie! Überlegungen zur Biographik in der Künstlerinnenforschung ", Kunstchronik: Monatsschrift für Kunstwissenschaft, Museumswesen u. Denkmalpflege, $\mathrm{n}^{\circ} 55$ (2002), p. 170) impulse la dynamique du livre présent en plaidant pour des approches qui se détachent de la biographie dans une perspective féministe. En effet, les rapports de pouvoir vis-à-vis de la gent masculine, les efforts pour s'auto-affirmer sont mis en regard d'Otto Dix, connaissance personnelle d'Elfriede Lohse-Wächtler, souvent rapproché de Grethe Jürgens dans la critique et manifestant également une propension à reproduire le même type de portraits. Le but est ainsi, pour reprendre Ingrid von der Dollen (Elfriede Lohse-Wächtler: Im Mittelpunkt steht der Mensch, Berlin, 2002), d'extraire les deux femmes de leur double disparition, dues non seulement à leur genre mais aussi à leur avilissement dans l'art dégénéré. L'étude, loin de se limiter à l'output artistique, inclut une analyse discursive des récits ayant participé de la construction de mythifications ainsi que des photographies et s'intègre dans les études culturelles l'intersection de l'histoire de l'art, de la sociologie de la culture et de la sémiotique. Cette supradiscipline n'est toutefois repérable que dans la bibliographie (Brigitte Hipfl, " Jacques Lacan: Subjekt, Sprache, Bilder, Begehren und Fantasien », Andreas Hepp, Friedrich Krotz, Tanja Thomas (éd.), Schlüsselwerke der Cultural Studies, Wiesbaden: VS Verlag für Sozialwissenschaften, 2009, p. 83-93) et non dans le cours du livre, alors qu'elle serait pertinente dans la problématisation.

\section{INDEX}

Thèmes : Histoire de la culture, Histoire de l'art, Histoire des femmes

Index chronologique : Epoque contemporaine

\section{AUTEUR}

HÉLOÏSE ELISABETH DUCATTEAU

Sciences Po Paris (campus de Nancy) 